\title{
ANALISIS KINERJA SITUS WEB PERUSAHAAN ASURANSI UMUM TERBUKA Studi Kasus: 8 (delapan) Perusahaan Asuransi Umum Terbuka di Indonesia
}

\author{
Brata Wibawa Djojo \\ Jurusan Manajemen, Fakultas Ekonomi dan Komunikasi, BINUS University \\ Jln. K.H. Syahdan No. 9, Palmerah, Jakarta Barat 114804 \\ brata@binus.ac.id
}

\begin{abstract}
The company's product and service can be uploaded and accessed in website. It will make the customer easier to find for any information of product offered or about the company itself through company's website. Product(s) and service(s) information of the general insurance company in the website are the important things to make their customer learn about the product, know the company and (perhaps) make a transaction on there. This research is to measure the website performance of the go-public general insurance companies: how they fulfill the customer expectation of the information and service provided in their website properly. The research uses a non-statistical method, Quality Function Deployment (QFD) methodology. It uses House of Quality tool in graph and matrices to gather the Voice of Customer (VoC) for customer's requirements of website performance and the Voice of the Engineer (Technical Requirements), which is described for the website characteristic in terms of the function itself. Through this analysis, it will be set the development targets of the website performance of 8 (eight) go-public general insurance companies in Indonesia. It may be as an input for each company to review their website performance further.
\end{abstract}

Keywords: House of Quality, Voice of Customer (VoC), technical parameter, Quality Function Deployment, gopublic insurance companies

\begin{abstract}
ABSTRAK
Informasi mengenai produk dan jasa suatu perusahaan dapat diunggah dan diakses melalui situs web. Hal ini akan membuat pelanggan lebih mudah untuk mencari setiap informasi produk yang ditawarkan, atau mengenai perusahaan itu sendiri. Informasi produk dan jasa perusahaan asuransi umum di situs web merupakan suatu hal penting yang dapat memberikan kesempatan bagi pelanggan/calon pelanggan untuk mengetahui dan belajar tentang produk yang ditawarkan, tentang perusahaan dan (mungkin) dapat melakukan transaksi di situs tersebut. Penelitian ini mengukur kinerja situs web dari perusahaan asuransi umum terbuka di Indonesia: bagaimana mereka memenuhi kebutuhan pelanggan dengan baik terhadap informasi dan layanan yang diberikan di situs web. Penelitian menggunakan metode non-statistik, Metodologi Quality Function Deployment (QFD). QFD menggunakan alat pengukuran House of Quality (HOQ) dalam bentuk grafik dan matriks untuk mendapatkan Suara Pelanggan atas kebutuhan/harapan pelanggan terhadap kinerja situs web dan Suara Mekanik/Parameter Teknik yang diaplikasikan untuk memenuhi kinerja situs web. Melalui analisis ini, diperoleh target pengembangan dari kinerja situs web 8 (delapan) perusahaan asuransi umum terbuka di Indonesia. Hal ini diharapkan dapat menjadi masukan bagi setiap perusahaan untuk mengevaluasi kinerja situs web mereka pada masa mendatang.
\end{abstract}

Kata kunci: House of Quality, suara pelanggan, Parameter Teknis, Quality Function Deployment, Perusahaan Asuransi Umum Terbuka 


\section{PENDAHULUAN}

Informasi adalah kekuatan untuk memenangkan persaingan. Bagi kebanyakan perusahaan saat ini, penggunaan situs web sebagai sarana penyebaran informasi mengenai produk dan jasa yang ditawarkan kepada pelanggan merupakan keunggulan tersendiri. Pelanggan dapat mencari informasi perusahaan dan produk/jasa yang ditawarkan serta melakukan simulasi atau transaksi secara on-line melalui situs web perusahaan secara mandiri. Tuntutan dan kebutuhan pelanggan terhadap kinerja dan kualitas situs web semakin tinggi.

Kebutuhan pelanggan akan informasi pada perusahaan asuransi umum, khususnya perusahaan asuransi umum terbuka di Indonesia merupakan kebutuhan yang perlu diperhatikan, mengingat bahwa produk asuransi umum tidak selalu dikenal oleh masyarakat di Indonesia, terutama terhadap apa yang menjadi jaminan dan apa yang dikecualikan. Pelanggan (yang disebut sebagai Tertanggung) juga perlu mengetahui kondisi perusahaan asuransi (perusahaan) terutama terhadap kinerja keuangan perusahaan agar merasa yakin dan aman ketika telah mengasuransikan asetnya di perusahaan tersebut, bagaimana proses klaim, dan apa yang menjadi kelebihan dari produk yang dibelinya.

Sering kali apa yang menjadi kebutuhan pelanggan terhadap kinerja situs web tidak sesuai dengan kenyataan dan bahkan tidak ada komunikasi dari pelanggan untuk menyampaikan apa yang diharapkan terhadap kinerja situs web, walaupun pada situs web ada kolom saran yang dapat diinput oleh pelanggan pada saat itu juga. Hal ini bisa disebabkan oleh beberapa faktor, di antaranya adalah adanya anggapan atau perkiraan dari pelanggan bahwa situs web tidak pernah di-update, sehingga memberikan saran juga tidak akan diperhatikan, atau dapat juga karena para pelangaan yang tidak begitu peduli/tidak ada ide terhadap apa yang harus disampaikan, atau juga memang karena tim Teknologi Informasi (TI) perusahaan asuransi tidak tanggap terhadap masukan atau kebutuhan pelanggan.

\section{METODE PENELITIAN}

Quality Function Deployment (QFD) diciptakan pertama kali oleh Yoji Akao dan Shigeru Mizuno dengan nama aslinya, Hin-shitsu Kino Tenkai, yang belakangan ini dikaitkan oleh beberapa penelitian dengan alat ukur House of Quality (HOQ) untuk mendefinisikan Kebutuhan Pelanggan dan diterjemahkan ke dalam fitur produk secara spesifik untuk memenuhi kebutuhan tersebut (Merts, 2007). Akao (Wikimedia Foundation Inc, 2008b) menyampaikan bahwa QFD adalah suatu metode transformasi dari permintaan pelanggan menjadi kualitas desain, untuk pembentukan fungsi kualitas, untuk menyebarkan metode untuk mencapai kualitas desain melalui sub-sistem dan komponenkomponen, dan terutama untuk membuatkan spesifikasi proses pabrikasi. QFD Institute dalam situsnya (2008) menjelaskan bahwa metode QFD dianggap suatu metode yang baik untuk menganalisis kualitas suatu produk dan berbeda dengan metode kualitatif lainnya, karena mencakup kebutuhan pelanggan yang tercetuskan maupun yang tidak tercetuskan dan dapat memaksimalkan kualitas secara positip (seperti mudah digunakan, menyenangkan, kemewahan) dengan menciptakan nilai. Metode kualitatif lain biasanya hanya untuk meminimalkan kualitas negatif (seperti pelayanan yang buruk).

Kebutuhan Pelanggan adalah langkah pertama dan terpenting dalam matriks HOQ untuk diselesaikan terlebih dahulu (Lowe, 2000). Langkah ini akan mengetahui kebutuhan pelanggan secara langsung (Suara Pelanggan) dalam daftar terstruktur. Langkah selanjutnya adalah mengkuantifikasi prioritas Kebutuhan Pelanggan dan persepsi pelanggan terhadap kinerja produk saat ini dalam Planning Matrix, kemudian dinilai berdasarkan isu yang penting oleh tim QFD dengan melakukan 
pembobotan dan Improvement Factor. Langkah ketiga adalah mengidentifikasikan Parameter Teknik yang dapat diukur terhadap Kebutuhan Pelanggan, di mana karakteristik/atribut produk ditentukan oleh perusahaan dan didesain oleh tim QFD untuk memenuhi Kebutuhan Pelanggan secara spesifik. Menggali hubungan antara Kebutuhan Pelanggan dan Paramater Teknik adalah langkah terakhir sebelum melakukan setting Target Pengembangan terhadap produk/jasa yang dianalisis.

Tahap awal penelitian adalah dengan melakukan penyaringan terhadap objek perusahaan yang akan diteliti. Tercatat bahwa dari 86 perusahaan asuransi umum di Indonesia (Direktori Perasuransian Indonesia, 2010), hanya ada 9 perusahaan asuransi umum yang telah tercatat di Bursa Efek Indonesia, yaitu: PT. Asuransi Bintang Tbk. (AB), PT. Asuransi Bina Dana Arta Tbk. (ABDA), PT. Asuransi Dayin Mitra Tbk. (ADM), PT. Asuransi Harta Aman Pratama Tbk. (AHAP), PT. Asuransi Jasa Tania Tbk. (AJT), PT. Lippo General Insurance Tbk. (LGI), PT. Asuransi Multi Artha Guna Tbk (MAG), PT. Panin Insurance Tbk. (PI), dan PT. Asuransi Ramayana Tbk. (AR). Pada saat dilakukan penelitian dan dicoba beberapa kali, situs web AR tidak dapat dibuka, sehingga penelitian hanya menggunakan 8 perusahaan asuransi umum yang situs webnya dapat dibuka.

Untuk mengetahui Suara Pelanggan sebagai tahap awal untuk melakukan penelitian ini, maka disebarkan kuesioner dengan metode nonacak dengan Judgemental Sampling (Kumar, 2002, h.313) terhadap Tingkat Kepentingan Atribut Kegunaan/Kinerja Situs Web dan Tingkat Kepuasan Pelanggan. Pelanggan yang dimaksud di sini adalah setiap user yang mengerti dan dapat menggunakan Internet, termasuk mengerti terhadap istilah-istilah Internet. Penyebaran kuesioner dilakukan terhadap 2 (dua) kategori responden yaitu para manajer TI setiap perusahaan asuransi umum terbuka dan para responden yang mengerti dan fasih terhadap Internet. Dasar penetapan kategori tersebut adalah agar mendapatkan informasi yang akurat sesuai dengan praktek di lapangan (terhadap manajer TI) dan terhadap responden yaitu agar pengumpulan data tidak memihak (netral) ke salah satu perusahaan yang diteliti. Cara pengumpulan data yaitu dengan melalui interview singkat melalui telepon (khusus bagi para manajer TI) dan membandingkan tampilan pint-screen dari 8 (delapan) situs web perusahaan asuransi umum terbuka. Responden diminta untuk memberikan masukan terhadap kinerja situs web yang baik, lalu dari kriteria tersebut dikelompokkan dengan menggunakan Diagram Afinitas.

Kuesioner kemudian disusun dan dibagikan kepada responden. Pengolahan data kuesioner dengan menggunakan skala Likert (Skala Interval), yang terdiri dari 6 (enam) kategori skala: (1) sangat tidak setuju dan tidak ada hubungan dengan pertanyaan; (2) sangat tidak setuju; (3) tidak setuju; (4) setuju; (5) sangat setuju; (6) sangat setuju dan merekomendasikan untuk diaplikasikan.

Menurut Kumar (2002, h.258), penetapan kategori skala dimulai dari 2 hingga tidak terbatas, tergantung dari beberapa faktor, di antaranya kemampuan peneliti, format interview, dan sifat dari objek penelitian.

Jumlah responden yang dibagikan kuesioner adalah sebanyak 15 orang responden (Gambar 1. Usability Testing). Menurut Nielsen (2000, dikutip dari Nielsen dan Landauer, 1993, p. 206-213), perumusan dalam mencari berapa banyak web usability problem (dalam hal ini Kebutuhan Pelanggan) yang ditemukan dalam usability test adalah $\mathrm{N}\left(1-(1-\mathrm{L})^{\mathrm{n}}\right)$, di mana $\mathrm{N}$ adalah total banyaknya masalah dalam desain web, $\mathrm{L}$ adalah proporsional Kebutuhan Pelanggan yang ditemukan dalam tes kepada 1 orang pelanggan dan $n$ adalah jumlah pelanggan. Hasil suara dari 5 orang, didapat $75 \%$ kemiripan harapan/kebutuhan pelanggan. Ketika dikumpulkan suara terhadap 15 orang responden, hasilnya hampir 100\% terjadi kemiripan kebutuhan pelanggan. Jika dikumpulkan suara lebih dari 15 orang, maka waktu yang terbuang akan lebih banyak dibandingkan dengan mendapatkan hasil yang optimal. 


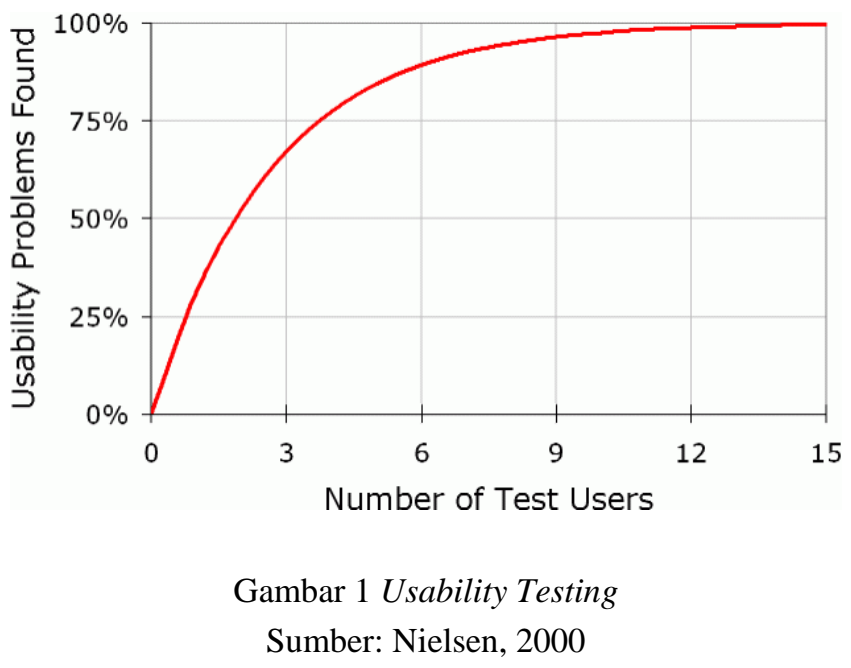

Penelitian ini menggunakan metode QFD dengan alat pengukuran matriks HOQ (Rumah Kualitas) yang terdiri dari 6 tahap:

Analisis terhadap Suara Pelanggan (VoC), dengan mengacu pada informasi yang didapat dari hasil respondensi untuk menetapkan atribut kinerja situs web. Kemudian dilakukan pengelompokkan dan pemilahan terhadap VoC (dengan Diagram Afinitas), mana yang dapat menjadi satu dan mana yang tidak berhubungan dengan topik, sebelum membagikan kuesioner.

Matriks Perencanaan: (a) untuk mengetahui dan mendapatkan Tingkat Kepentingan terhadap Suara Pelanggan, dilakukan penyebaran kuesioner dengan pendekatan Analytical Hierarchy Process (AHP) [Lowe, 2000] kepada para responden kemudian hasilnya dirata-rata dan kemudian dimasukkan ke dalam setiap komponen (sebagai Bobot Tingkat Kepentingan). (b) Kemudian dilakukan analisis perbandingan antar situs web perusahaan dengan target reponden baru, dengan kriteria: tidak bekerja di salah satu perusahaan yang diteliti (agar menjaga obyektifitas penelitian), mengerti dan memahami situs web, mempunyai waktu yang cukup untuk mengisi kuesioner dan melakukan perbandingan antar situs web (8 situs web). (c) Pengukuran selanjutnya adalah menentukan Rating Tingkat Kepuasan yang Direncanakan, Faktor Peningkatan (Improvement Factor), dan Poin Penjualan. Mengingat bahwa penelitian ini melakukan pembandingan antarproduk (situs web), maka sebagai asumsi atas nilai dari pengganti produk yang diteliti adalah nilai rata-rata dari keseluruhan produk. Termasuk di dalamnya adalah: Target Rating, adalah target yang ditetapkan agar dapat meningkatkan kinerja; Faktor Perbaikan adalah nilai dari Target Rating terhadap Rata-Rata Kinerja; Faktor Pembobotan adalah perkalian dari Faktor Perbaikan dengan Tingkat Kepentingan (Rampersard, 2005, h153).

Parameter Teknis; ditentukan berdasarkan kebutuhan teknis terhadap atribut situs web dan kemudian dikelompokkan. Setiap atribut diberikan simbol berupa anak panah untuk menunjukkan apakah perlu untuk ditingkatkan atau dikurangi.

Matriks Antar-Hubungan; merupakan penggabungan antara VoC dengan Parameter Teknik yang telah ditentukan sebelumnya. Analisis yang dilakukan adalah menentukan apakah adanya hubungan yang signifikan antara kedua faktor tersebut dan diberikan pembobotan atas pertimbangan dari tim peneliti berdasarkan skala: tinggi, menengah, rendah, tidak ada. Skala tersebut dapat dipresentasikan dengan menggunakan simbol. Tiap skala diberikan skor pembobotan: Tinggi (9), Menengah (3), Rendah (1), Tidak Ada (0). Pembobotan ini akan dipakai dalam menentukan Target pada tahap akhir analisis HOQ. Terhadap atribut yang memiliki hubungan, dilakukan analisis hubungan dengan menghitung skor antara Target Rating dibandingkan dengan Total Target Rating terhadap Poin Matriks Antar-Hubungan. 
Atap HOQ; pemetaan hubungan antar-Parameter Teknik dapat dilakukan melalui atap HOQ, di mana hubungan sangat kuat dan positif kuat ditandai dengan tanda positif ganda $(++)$, hubungan kuat dan positif (+), hubungan kuat dan negatif (-) dan hubungan yang lemah ditandai dengan tanda negatif ganda (--), sedangkan jika tidak ada hubungan maka dikosongkan. Tujuan dari pemetaan hubungan ini adalah untuk mengetahui perbaikan apa saja yang perlu diperhatikan dan mewakili peluang dan inovasi produk.

Target; terdiri dari 3 bagian: (a) Prioritas Teknik - dengan melakukan pembobotan pada perencanaan dan matriks antar hubungan, (b) Competitive benchmark sebagai indetitas karakteristik mana yang terpenting dari antar produk, (c) Target itu sendiri yang merupakan hasil final terhadap kinerja situs web yang seharusnya sesuai dengan kebutuhan pelanggan.

\section{HASIL DAN PEMBAHASAN}

\section{Analisis terhadap Suara Pelanggan (VoC)}

Tabel 1 menunjukkan hasil pengolahan data terhadap 7 macam pengelompokan atribut kinerja situs web: context, content, community, customization, communication, connection, dan commerce. Masing-masing atribut memiliki angka terhadap Tingkat Kepentingan (TK) terhadap kinerja situs web dan dibandingkan dengan Tingkat Kinerja pada masing-masing perusahaan. Setiap atribut situs web pada 8 perusahaan, dilakukan perhitungan rata-rata bobot. Tujuannya adalah untuk mengetahui atribut mana yang menjadi pokok perhatian selama ini bagi mayoritas perusahaan dan sebagai dasar dalam perhitungan Target Pengembangan pada Matriks Perencanaan.

Tingkat kepentingan tertinggi berdasarkan hasil pengolahan data dapat dilihat pada Tabel 1 tersebut, di mana atribut 'Cepat Diakses/download' memiliki poin tertinggi sebesar 5,9 (dari skala 6) dan atribut 'Banner Promosi' memiliki poin terendah sebesar 3,3 (dari skala 6). Atribut tersebut berdasarkan Suara Pelanggan (VoC) yang dapat dijadikan review dan acuan bagi perusahaan dalam mengembangkan proyek situs web. Sedangkan rata-rata Tingkat Kinerja atribut tertinggi (dari 8 perusahaan) atribut 'Cepat Diakses/download' menempati urutan tertinggi (poin 5,0) dan 'Dapat melakukan transaksi online' menduduki peringkat terakhir (poin 2,9). Tabel lebih detail yang menunjukkan hasil dari suara pelanggan dan rata-rata atribut dapat dilihat pada Lampiran.

\section{Matriks Perencanaan}

Hasil dari pembobotan pada Matriks Perencanaan dapat dilihat pada Tabel 2, di mana 'Dapat melakukan transaksi online' adalah atribut situs web tertinggi yang menjadi rekomendasi untuk diaplikasikan pada situs web perusahaan, diikuti dengan atribut 'Ada fitur simulasi'. Sedangkan atribut 'Banner Promosi' dan 'Tidak ada pembatasan ke setiap halaman' merupakan atribut situs web yang tidak populer untuk direkomendasikan. 
Tabel 1 Suara Pelanggan

\begin{tabular}{|c|c|c|c|c|c|c|c|c|c|c|c|}
\hline No & Attribut Situs Web & $T K$ & $\stackrel{\infty}{q}$ & 氐 & $\underset{d}{\frac{Z}{d}}$ & $\stackrel{\searrow}{Z}$ & $\stackrel{5}{k}$ & త్త & $\sum_{i}^{\infty}$ & $\bar{\Sigma}$ & 妾点 \\
\hline & Context & & & & & & & & & & \\
\hline 1 & $\begin{array}{l}\text { Warna yang digunakan sesuai dengan ciri produk } \\
\text { yang dijual dan budaya perusahaan }\end{array}$ & 5.1 & 3.9 & 3.5 & 3.7 & 4.1 & 4.6 & 3.5 & 4.0 & 3.9 & 3.9 \\
\hline 2 & $\begin{array}{l}\text { Situs web harus interaktif } \\
\text { Content }\end{array}$ & 5.6 & 3.9 & 4.1 & 2.9 & 4.1 & 5.3 & 3.7 & 4.5 & 3.9 & 4.1 \\
\hline 3 & Mempunyai multimedia dalam halaman situs & 4.8 & 3.5 & 3.9 & 2.9 & 5.0 & 4.8 & 3.3 & 4.8 & 4.7 & 4.1 \\
\hline 4 & Informasi disertai dengan grafik/gambar & 5.3 & 3.4 & 3.5 & 3.1 & 4.1 & 5.3 & 3.4 & 4.1 & 4.9 & 4.0 \\
\hline 5 & $\begin{array}{l}\text { Mempunyai banner promosi } \\
\text { Community }\end{array}$ & 3.3 & 3.2 & 3.5 & 3.1 & 3.6 & 4.5 & 3.3 & 4.7 & 4.1 & 3.8 \\
\hline 6 & $\begin{array}{l}\text { Ada login keanggotaan } \\
\text { Customization }\end{array}$ & 4.9 & 3.1 & 3.4 & 3.0 & 4.4 & 3.0 & 3.0 & 4.2 & 3.1 & 3.4 \\
\hline 7 & Tidak ada pembatasan ke setiap halaman & 4.7 & 4.3 & 4.7 & 3.9 & 4.9 & 4.9 & 4.9 & 4.8 & 4.9 & 4.7 \\
\hline 8 & $\begin{array}{l}\text { Ada fitur simulasi } \\
\text { Communication }\end{array}$ & 5.5 & 3.1 & 3.1 & 2.9 & 5.3 & 3.5 & 3.6 & 3.2 & 3.4 & 3.5 \\
\hline 9 & Mudah dibaca & 5.5 & 4.3 & 4.1 & 3.5 & 4.1 & 4.1 & 3.7 & 4.1 & 4.1 & 4.0 \\
\hline 10 & Mudah dipelajari/diingat & 5.4 & 4.2 & 4.2 & 3.5 & 4.5 & 5.1 & 4.2 & 4.4 & 4.7 & 4.4 \\
\hline 11 & $\begin{array}{l}\text { Menginformasikan produk/jasa dengan baik } \\
\text { Connection }\end{array}$ & 5.7 & 2.6 & 4.5 & 3.0 & 5.4 & 5.6 & 3.7 & 4.9 & 5.2 & 4.4 \\
\hline 12 & Ada navigasi & 5.1 & 4.1 & 4.4 & 2.9 & 4.3 & 4.6 & 4.5 & 4.5 & 4.6 & 4.2 \\
\hline 13 & Mudah Melakukan pencarian (fasilitas Search) & 5.3 & 4.3 & 4.5 & 2.9 & 4.4 & 5.3 & 3.7 & 4.0 & 4.5 & 4.2 \\
\hline 14 & Cepat diakses / download & 5.9 & 4.9 & 4.9 & 4.9 & 5.0 & 5.4 & 5.2 & 4.2 & 5.3 & 5.0 \\
\hline 15 & Tidak ada Error Page & 5.5 & 4.5 & 4.3 & 2.5 & 4.6 & 5.5 & 3.3 & 3.0 & 4.9 & 4.1 \\
\hline 16 & Halaman tidak berdiri sendiri & 5.3 & 3.1 & 4.2 & 3.5 & 4.7 & 5.3 & 4.0 & 3.8 & 4.5 & 4.1 \\
\hline 17 & $\begin{array}{l}\text { Mempunyai Peta Situs } \\
\text { Commerce }\end{array}$ & 4.1 & 3.0 & 3.3 & 2.5 & 2.8 & 4.8 & 3.1 & 4.4 & 4.1 & 3.5 \\
\hline 18 & Dapat melakukan transaksi online & 5.1 & 2.7 & 2.9 & 2.7 & 3.2 & 3.2 & 2.9 & 3.1 & 2.7 & 2.9 \\
\hline
\end{tabular}

Keterangan: TK= Tingkat Kepentingan

Sumber: Hasil Pengolahan Data

Tabel 2 Atribut Situs Web yang menjadi Rekomendasi untuk Diaplikasikan

\begin{tabular}{lc}
\hline \multicolumn{1}{c}{ Atribut situs web } & Rasio Pembobotan \\
\hline Dapat melakukan transaksi online & $7.2 \%$ \\
Ada fitur simulasi & $7.0 \%$ \\
Tidak ada Error Page & $6.5 \%$ \\
Menginformasikan produk/jasa dengan baik & $6.4 \%$ \\
Situs web harus interaktif & $6.2 \%$ \\
Halaman tidak berdiri sendiri & $6.2 \%$ \\
Mudah dibaca & $6.1 \%$ \\
Ada login keanggotaan & $5.8 \%$ \\
Cepat diakses / download & $5.7 \%$ \\
Informasi disertai dengan grafik/gambar & $5.7 \%$ \\
Mudah dipelajari/diingat & $5.5 \%$ \\
Mudah Melakukan pencarian (fasilitas Search) & $5.4 \%$ \\
Warna yang digunakan sesuai dengan ciri produk yang & $5.3 \%$ \\
dijual dan budaya perusahaan & $5.3 \%$ \\
Ada navigasi & $4.5 \%$ \\
Mempunyai multimedia dalam halaman situs & $4.3 \%$ \\
Mempunyai Peta Situs & $4.1 \%$ \\
Tidak ada pembatasan ke setiap halaman & $2.7 \%$ \\
\hline Mempunyai banner promosi &
\end{tabular}

Sumber: Hasil Pengolahan Data 


\section{Parameter Teknis}

Setelah mengumpulkan referensi dan mendapatkan masukkan dari beberapa perusahaan, ditentukan atribut Parameter Teknis sebagai berikut: Update berkala, Online 24 jam, Keamanan Jaringan, Registrasi Situs Web, Ukuran Kapasitas pada halaman situs web, Web Server tersedia dan terawat dengan baik, Hypertext Markup Language (HTML) dan bahasa pemrograman yang baik, dan Training terhadap tim TI pembuat situs web.

Hubungan yang sangat kuat dan positif adalah hubungan antara atribut: Update berkala dan Training terhadap tim TI pembuat situs web; Online 24 jam dan Keamanan jaringan; Online 24 jam dan Web Server tersedia dan terawat dengan baik; Keamanan jaringan dan Web Server tersedia dan terawat dengan baik; HTML dan bahasa pemrograman yang baik dan Training terhadap tim TI pembuat situs web. Sedangkan hubungan yang sangat kuat dan negatif adalah terhadap atribut Ukuran Kapasitas pada halaman situs web dan Training terhadap tim TI pembuat situs web, Ukuran Kapasitas pada halaman situs web dan HTML dan bahasa pemrograman yang baik.

\section{Matriks Antar-Hubungan}

Dari hasil penelitian, ditemukan bahwa atribut Parameter Teknis yang lebih banyak berhubungan dengan atribut VoC adalah 'Training terhadap tim pembuat situs web', di mana setiap atribut VoC mempunyai hubungan dengan atribut ini. Atribut Parameter Teknik kedua yang banyak berhubungan dengan atribut VoC adalah 'HTML dan bahasa pemrograman yang baik' dan kemudian atribut 'Ukuran Kapasitas'. Hal ini berarti bahwa untuk setiap apa pun keinginan pelanggan terhadap kinerja situs web, perusahaan harus memperhatikan keterampilan dan kemampuan tim TI (khususnya yang mengembangkan situs web) dan perlu memberikan kesempatan training; tidak hanya training terhadap teknis TI, namun juga termasuk training terhadap pengetahuna produk asuransi. Atribut kedua yang perlu diperhatikan adalah bagaimana bahasa program situs web (HTML) dan program lainnya dapat mendukung dan mengeksplorasi pengembangan situs web agar dapat dibuat se-interaktif mungkin.

\section{Atap HOQ}

Hubungan yang Sangat Kuat dan Positif terjadi pada atribut Parameter Teknis atas: 'Online 24 jam' dan 'Keamanan Jaringan', dengan tersedianya layanan online 24 jam yang artinya bahwa pelanggan dapat mengakses situs web kapan saja, maka keamanan jaringan perlu diperhatikan oleh perusahaan, terutama agar tidak terjadi pembobolan atau korupsi data ketika sudah tidak ada yang bekerja (pulang). 'Online 24 jam' dengan 'Web server tersedia dan dirawat dengan baik', dengan layanan online 24 jam, maka perusahaan harus memperhatikan bahwa web server harus terawat dengan baik, agar situs web tetap dapat diakses. 'Keamanan Jaringan' dengan 'Web server tersedia dan dirawat dengan baik', Keamanan jaringan merupakan syarat mutlak agar web server dapat berjalan dengan baik. Web server yang terawat akan dapat memberikan dukungan keamanan jaringan yang baik. 'HTML dan bahasa pemrograman yang baik' dengan 'Training terhadap tim pembuat situs web'. Agar tim pembuat situs web (atau tim TI) dapat melakukan inovasi dan pengembangan situs web dengan baik, maka diperlukan suatu pelatihan - yang tidak hanya di bidang TI, namun juga di bidang perasuransian dan produk asuransi.

Sedangkan hubungan Sangat Kuat dan Negatif terjadi pada atribut: 'Ukuran kapasitas (halaman situs/multimedia)' dengan 'HTML dan bahasa pemrograman yang baik'. Bahasa pemrograman yang baik dapat meminimalkan ukuran kapasitas dari halaman situs, termasuk penempatan multimedia yang tepat. 'Ukuran kapasitas (halaman situs/multimedia)' dengan 'Training terhadap tim pembuat situs web’. Semakin luas tingkat pengetahuan tim pembuat situs web, maka akan dapat meminimalkan ukuran kapasitas halaman situs web, mengingat semakin besar kapasitasnya, maka akan semakin lambat bagi seorang pelanggan untuk mengakses situs tersebut. 


\section{Target}

Prioritas Teknis; walaupun pelatihan terhadap tim pembuat situs web merupakan atribut yang selalu berhubungan dengan setiap atribut VoC (poin 5,5 atau 21,5\%), namun parameter teknis yang harus lebih diperhatikan dan mempunyai antar hubungan yang tinggi adalah bahasa pemrograman (HTML) agar dapat membuat situs web lebih interaktif dan memenuhi kinerja yang diharapkan oleh pelanggan (poin 6,7 atau 26,2\%). Sedangkan Registrasi Situs Web (poin 1,4 atau 5,3\%) merupakan atribut terkecil.

Competitive Benchmarking; dari hasil survei dan pengumpulan data, hampir semua perusahaan asuransi umum melakukan outsourcing untuk membuat dan mengembangkan situs web tersebut sehingga training yang dilakukan untuk tim pembuat situs web tidak dilakukan oleh perusahaan asuransi, untuk ADM dan AJT, situs web sudah lama tidak di-update. Tidak semua situs dapat online 24 jam, terutama pada saat libur panjang, akses ulang yang dilakukan pada tanggal 29 September 2008, situs web untuk AB, ADM, dan AJT tidak dapat dibuka. Beberapa halaman situs web yang memiliki kapasitas di atas 10KB adalah AB, ABDA, AHAP, dan PI. Perusahaan lainnya rata-rata kapasitas halaman sebesar 4-10 KB. Untuk atribut bahasa pemrograman, AB, ABDA, dan LGI menggunakan XHTML versi 1.0, sisanya menggunakan DHTML versi 4.0.

Nilai Target yang ditetapkan; target yang ditetapkan dari hasil pengolahan data atas VoC adalah: (a) Update berkala dapat dilakukan, minimal 1 kali dalam sebulan atau bilamana ada acara kegiatan/event yang dilakukan perusahaan untuk dipromosikan. (b) Online 24 jam agar pelanggan dapat berinteraksi kapan saja mereka inginkan. (c) Keamanan jaringan diaplikasikan sesuai kebutuhan dan fungsi situs web. Jika pelanggan dapat melakukan login dan transaksi di sana, maka tingkat keamanan jaringan harus ditingkatkan dibandingkan dengan hanya berupa situs web biasa. (d) Ukuran kapasitas pada halaman situs web/multimedia yang terdapat di dalamnya perlu menjadi perhatian agar tidak terlalu besar sehingga menyebabkan bottleneck sehingga situs sulit diakses. Ukuran yang dianjurkan tidak melebihi $10 \mathrm{~KB}$ per halaman situs web. (e) Web server tersedia dan terawat dengan baik. Sering kali, karena fungsinya yang tidak dirasakan optimal, pengembangan situs web tidak direncanakan dengan baik dengan menyediakan web server khusus dan terpisah dengan server lainnya. Perawatan yang baik termasuk juga melakukan instalasi terhadap software antivirus, antihacker, dan keamanan lainnya. (f) HTML dan bahasa pemrograman yang baik: minimal yang dibutuhkan adalah HTML, JavaScript (Visual Basic/php). (g) Training terhadap tim pembuat situs web perlu dilakukan secara periodik, agar menambah pengetahuan tim terhadap perkembangan teknologi terbaru dan dunia perasuransian.

\section{SIMPULAN}

Terhadap pengembangan situs web, penggunaan banner promosi, peta situs, dan multimedia menjadi prioritas terakhir setelah perusahaan merasa yakin bahwa situs web yang dimilikinya dapat dengan mudah dan cepat diakses dan menginformasikan produk/jasa dengan baik. Bahasa pemrograman situs web (HTML, Java Script, php, dan lainnya) perlu dikembangkan untuk membuat situs web menjadi lebih interaktif. Training secara periodik kepada tim pengembang situs web atau tim TI terhadap masalah teknologi terbaru dan produk asuransi perlu dilakukan. 


\section{DAFTAR PUSTAKA}

Bapepam-LK. (2010). Direktori Perasuransian Indonesia 2010. Jakarta: Direktorat Asuransi, Departemen Keuangan Indonesia.

Kumar, V., AAker, David A. \& Day, George S. (2002). Essentials of Marketing Research. $2^{\text {nd }}$ Ed. Danvers (DV): John Wiley \& Sons, Inc.

Lowe, A.J. (2000). House of Quality (QFD) Tutorial. [Online] New South Wales: Center of Management Innovation \& Technology, Graduate School of Management Macquarie University, diakses 2 Oktober 2008 dari http://www.gsm.mq.edu.au/cmit/qfd-hoq-tutorial.swf

Merts, Joseph P. (2007). Where Did QFD Get Its Terrible Name? [Online] 12 June, diakses 4 Oktober 2008 \& 3 Januari 2012 dari http://www.qfdonline.com/archives/category/history-of-qfd/

Nielsen, Jakob. (2000). Usability Testing with 5 Users. [Online] Jakob Nielsen's Alertbox, diakses 7 Oktober 2008 dari http://www.useit.com alertbox 20000319.html

Norman, Rick. (2008). QFD Process - QFD is more than drawing the Planning House of Quality. [Online] QFDCapture.com., diakses 4 Oktober 2008 \& 3 Januari 2012 dari http://www.qfdcapture.com/qfdprocess.asp

Rampersad, Hubert K. (2005). Total Performance Scorecard. Jakarta: Gramedia Pustaka Utama.

Wikimedia Foundation, Inc. (2008b). Quality function deployment - Wikipedia, the free encyclopedia [Online] (Update 15 September 2008), diakses 25 September 2008 dari http://en.wikipedia.org/wiki/Quality_function_deployment.htm 


\section{LAMPIRAN}

Tabel Quality Function Deployment

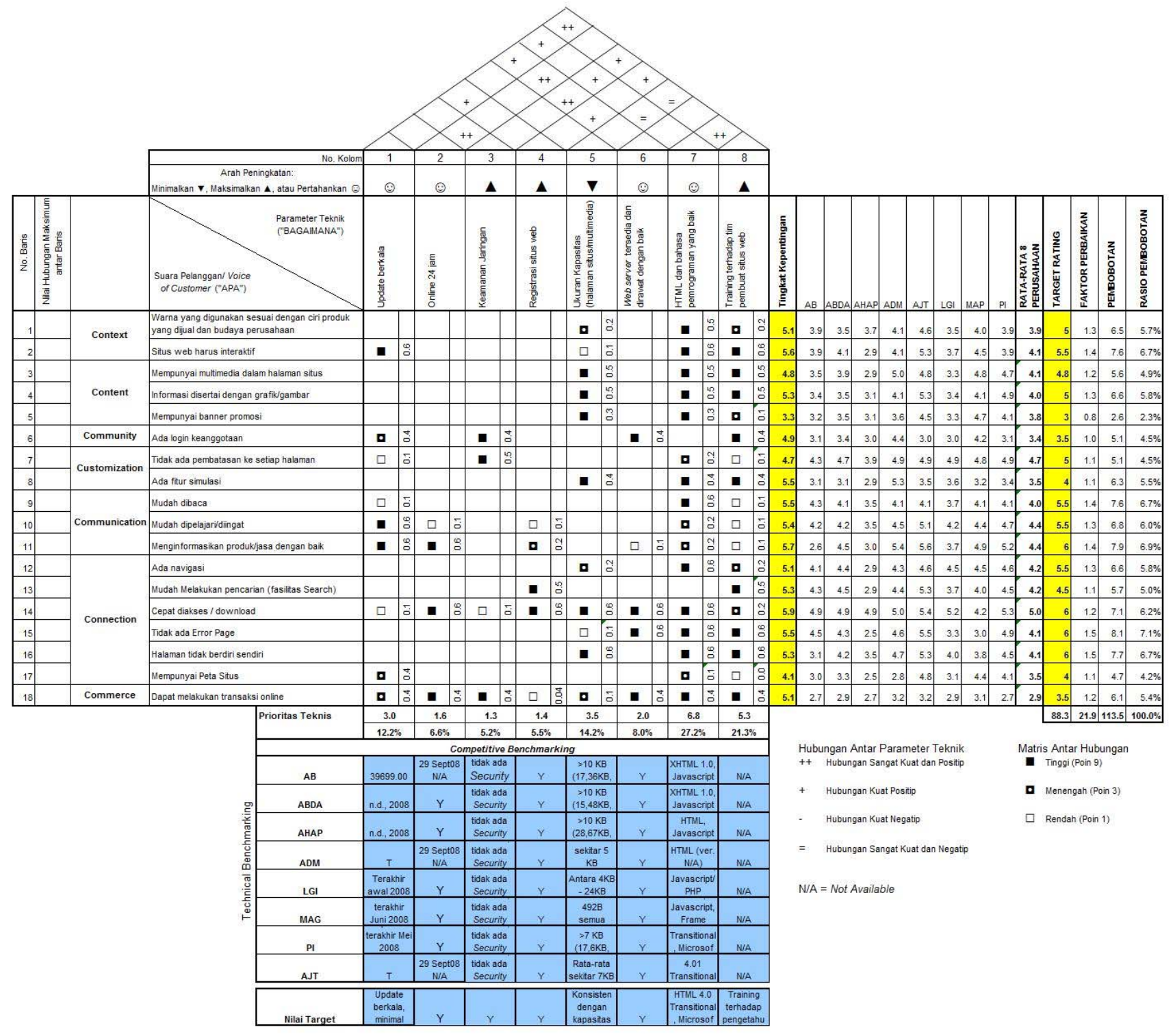

Sumber: Hasil pengolahan data 